\title{
A New Bumping Danger Warning Method Based on the Growth Trend of Drilling Cutting Quantity
}

\author{
Zhongcheng Qin \\ College of Mining and Safety Engineering \\ Shandong University of Science and \\ Technology, \\ Qingdao, China \\ email: qinzhch@126.com
}

Bin Cao

College of Mining and Safety Engineering

Shandong University of Science and

Technology,

Qingdao, China

email: 2279320946@qq.com

\author{
Tan $\mathrm{Li}$ \\ College of Mining and Safety Engineering \\ Shandong University of Science and \\ Technology, \\ Qingdao, China \\ email: litan597@163.com \\ Yuteng Liu \\ College of Mining and Safety Engineering \\ Shandong University of Science and \\ Technology, \\ Qingdao, China \\ email:914703253@qq.com
}

\author{
Guangbo Chen \\ College of Mining and Safety Engineering \\ Shandong University of Science and \\ Technology, \\ Qingdao, China \\ email: 1295458017@qq.com
}

\begin{abstract}
The method of drilling bits is a common method to predict the rockburst. This method establishes a quantitative relationship between the drilling cutting quantity and the stress in coal body. But in the process of mining, the common early warning indicator often has some disadvantages such as limitation and hysteretic nature due to some limiting factors. Taking the method of drilling bits as the theoretical basis and the No.3302 coalface of Xingcun coal mine as the engineering background, this paper proposes a new warning method and the new early warning indicator to make up for the limitations and hysteretic nature. The new early warning indicator is obtained by comparing the drilling cutting quantity before and after mining in the depth range of coal bodies with impact risk. Based on the variation trend of drilling cutting quantity and drilling rate warning indicator, the new real-time warning method is proposed. This method can be used to analyze the danger of rockburst in potential danger areas, which could be valuable in the design of rockburst resistant measures in deep buried construction.
\end{abstract}

Keywords-rockburst, method of drilling bits, drilling cutting quantity, drilling rate, warning indicator

\section{I . INTRODUCTION}

The method of drilling bits, as a common method, can obtain the drilling cutting quantity and coal body stress by drilling minor diameter boreholes (drilling bits detection holes) in the coal seams. It can predict the rockburst based on the quantitative relationship between the drilling cutting quantity and the coal stress. Many scholars have carried out the theoretical research, numerical simulation experiments and field measure experiments ${ }^{[1-6]}$. Pan Yishan et al. obtained a method for determining the drilling cutting quantity that can be used to predict the risk of rockburst in high gassy coal seams based on the characteristic of rock damage and influence of the gas ${ }^{[7]}$. Jiang Fuxing et al. established the relationship between drilling cutting quantity, bearing pressure, and coal stress through field measure experiments and method of numerical simulation ${ }^{[8]}$.

This paper was sponsored by the National Natural Science Foundation of China $(51379119,51304126)$
Through the efforts of many scholars, the variation of the drilling cutting quantity can be used to indicate the change of the coal stress, and can predict the risk of rockburst based on the dynamics phenomenon during the drilling process such as: drilling cutting quantity, the size of the drill cuttings and the sounds ${ }^{[9-10]}$. Among them, the drilling cutting quantity is an important indicator for the prediction of rockburst ${ }^{[11]}$. The early warning indicator for ordinary method of drilling bits is calculated by using the drilling rate and the drilling cutting quantity at unaffected area by mining, or the drilling cutting quantity early warning indicator is obtained through the statistics of a large number of on-site drilling data during the mining process ${ }^{[12]}$.

During the mining process, the drilling cutting quantity cannot reach the early warning indicator because the drilling depth is failure to reach the desire depth on account of some limiting factors. But it can reach the early warning indicator if the borehole deepens into the depth of coal and rock body. However, the method of drilling bits has the characteristics of timeliness, that is to say, although the drilling cutting quantity per meter is failure to reach the early warning indicator within the influence range of effective drilling depth, there is still the possibility of reaching the early warning indicator. Because the borehole test area is still affected by stress concentration caused by mining after completion of the test $\operatorname{work}^{[13]}$.

In order to solve the above problems, this paper uses the Xingcun coal mine as a background and proposes a new method of using the variation trend of drilling cutting quantity to predict the rockburst based on drilling rate.

\section{II . XINGCUN COAL MINE ENGINEERING GEOLOGICAL CONDITION}

The No. 3302 coalface in Xingcun coal mine is buried depth $1190-1280 \mathrm{~m}$, the dip angle of coal seam is 1-13 degrees, the average thickness of coal seam is $8.2 \mathrm{~m}$, and the Platts' coefficient $f$ is $4-6$, which has a strong tendency of rockburst. The coal seam roof is $5-20 \mathrm{~m}$ thick multilayer hard rock, and the Platts' coefficient $f$ is 6-11, which has a weak tendency of rockburst. And the combination of coal and old roof has the strong tendency of rockburst. In addition, the No. 3302 coalface is a deep-buried "two-hard" 
(hard roof, hard coal seam) mining conditions, the fractures overlying hard rock can easily induce dynamic disasters such as mine earthquake and rockburst.

\section{ANALYSIS OF DRILLING CUTTING QUANTITY AT UNAFFECTED AREA BY MINING}

The drilling cutting quantity was measured at the interval of 250-290 $\mathrm{m}$ from the opening of the haulage gate in the No. 3302 coalface. There were total of 5 boreholes tested, with the inspection depth of $15 \mathrm{~m}$ per borehole, one test data per one meter was obtained, and a total of 75 test data were collected through the gravimetric method. The drilling cutting quantity curve is shown in Fig. 1.

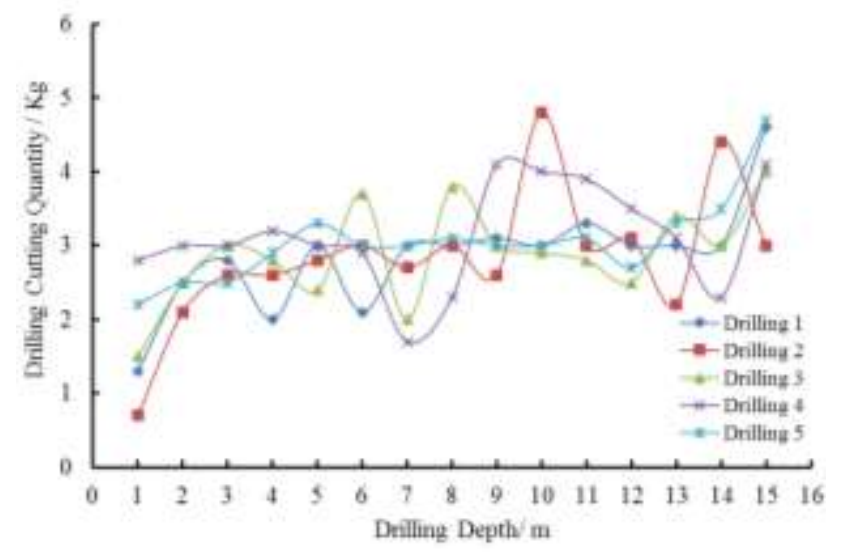

Fig. 1 Curve of drilling cutting quantity at unaffected area by mining

It can be seen from the Fig. 1, the drilling cutting quantity slowly increases with drilling depth. The drilling cutting quantity at the drilling depth of $1 \mathrm{~m}$ is significantly lower than that at other depths, because of the plastic deformation of the coal wall at this position, the construction resistance is small, these reasons lead to decrease of drilling cutting quantity. Because the stress concentration appears within the drilling depth of 8-12 m, there is a certain fluctuation of drilling cutting quantity. The average drilling cutting quantity was obtained based on the drilling cutting quantity in five boreholes. The relationship curve between the average drilling cutting quantity and drilling depth is shown in Fig. 2. It can be seen that the average drilling cutting quantity increases with the depth of the borehole, and the curve has a peak at the drilling depth of $10 \mathrm{~m}$. The simple function is fitted according to the trend curve of the average drilling cutting quantity with the drilling depth, the mathematical expression $y_{0}$ is:

$$
y_{0}=0.0666 x+1.95\left(R^{2}=0.728\right)
$$

where $x$ is the drilling depth; $y_{0}$ is the drilling cutting quantity at unaffected area by mining.

Based on the curve function of variation of the drilling cutting quantity per meter and drilling rate, the early warning indicator function $y_{1}$ of the drilling cutting quantity can be obtained. The relationship curve between the average drilling cutting quantity and early warning indicators is shown in Fig. 3.

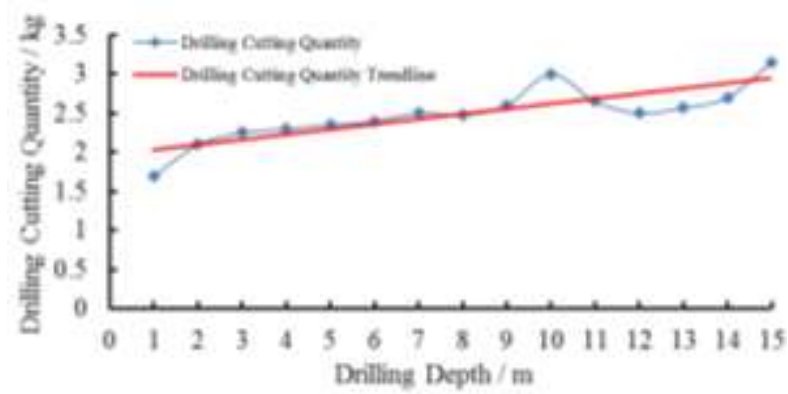

Fig. 2 Variation trend of average drilling cutting quantity

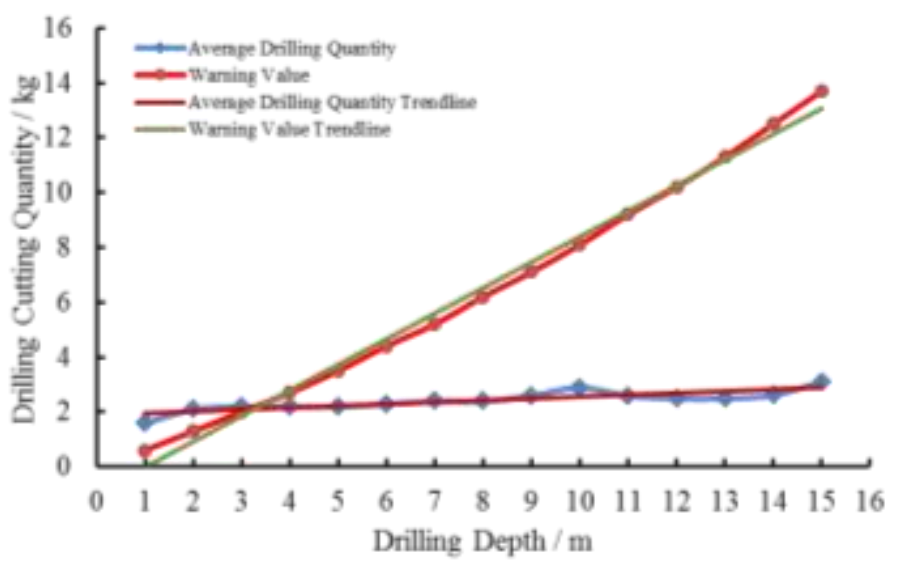

Fig. 3 Curve of drilling cutting quantity warning indicator

Because the No. 3302 coalface with the hard roof and hard coal seam adopts the mining method with large mining height and fully mechanize, it has the strong tendency of rockburst. According to the rules of the "Regulations on the prevention and control of rockburst in Shandong coal mine" on the drilling rate index, the drilling ratio = drilling depth / height of roadway. Based on the curve function of the drilling cutting quantity per meter and drilling rate, the function of the drilling cutting quantity warning indicator is:

$$
y_{1}=y_{0} * \frac{x}{3.2}=0.0208 x^{2}+0.61 x
$$

where $x$ is the drilling depth; $y_{1}$ is the early warning indicator of the drilling cutting quantity.

\section{IV . ANALYSIS OF DRILLING CUTTING QUANTITY AT AFFECTED AREA BY MINING}

During the period from April 16 to October 8, 2014, 169 boreholes within the influence range of advance bearing pressure before the No. 3302 coalface were detected, the detection depth is $12 \mathrm{~m}$ for each borehole, and 1 test data per meter was obtained by gravimetric method, a total of 75 test data were obtained, in order to seek the variation law of drilling cutting quantity per meter. Based on the lots of data obtained from field tests, five boreholes were randomly selected to draw the curve of drilling cutting quantity, as shown in Fig. 4. Because the drilling depth is failure to reach the stress peak region, drilling cutting quantity linear growth with the depth of the borehole, and abnormal growth is not appear. 


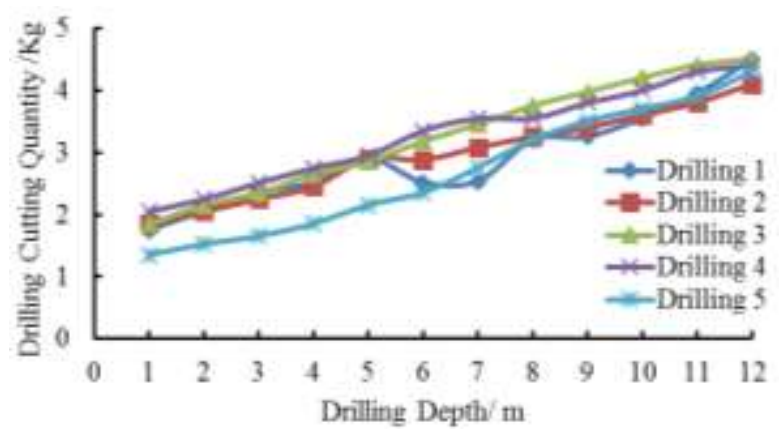

Fig. 4 Curve of drilling cutting quantity at affected area by mining

According to the statistical data, the mean value of drilling cutting quantity per meter is calculated from 169 drilling holes, and the distribution function of the drilling cutting quantity and the drilling depth is fitted:

$$
y_{2}=0.251 x+1.27\left(R^{2}=0.9994\right)
$$

where $x$ is the drilling depth; $y_{2}$ is the drilling cutting quantity at affected area by mining.

As shown in Fig. 5, the growth rate of drilling cutting quantity at affected area by mining is significantly higher than that of drilling cutting quantity at unaffected area by mining. The drilling cutting quantity at affected area by mining is not show an abnormal increase at the depth of drilling cutting quantity's peak at unaffected area by mining, because the stress peaks migrate to the deep part of the rock mass due to the mining influence, the drilling depth is too shallow to reach the range of peak stress.

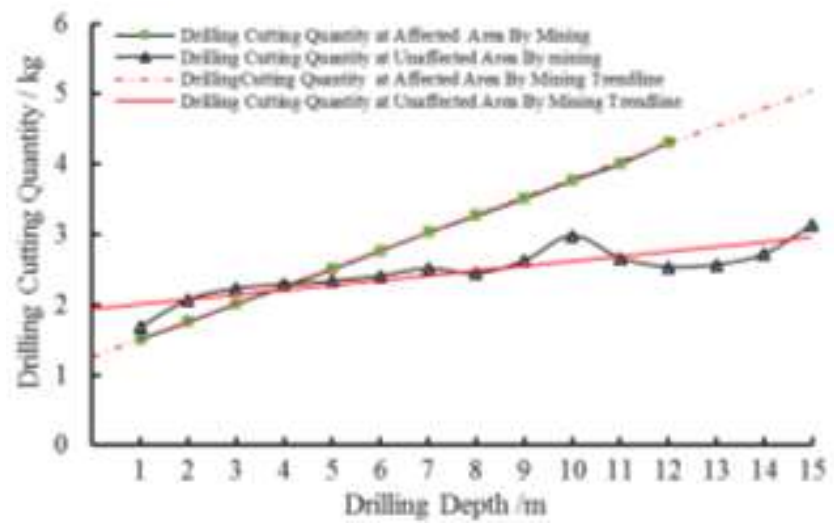

Fig. 5 Comparison curve of drilling cutting quantity before and after mining

\section{V . A NEW WARNING INDICATOR BASED ON THE VARIATION TREND OF DRILLING CUTTING QUANTITY}

During the mining process, the drilling depth cannot reach the ideal depth due to some limiting factors, so the drilling cutting quantity is failure to reach the early warning indicator. But the drilling cutting quantity will reach the early warning indicators if the borehole deepens into coal and rock masses. However, because the method of drilling bits has the characteristics of timeliness, the drilling cutting quantity per meter cannot reach the early warning indicator within the effective drilling depth, it is still possibility to reach the warning indicator if the testing area continues to be affected by the stress concentration caused by mining after the drilling. So, it is not precision enough to solely rely on the drilling cutting quantity to determine the early warning indicator during the drilling process. The variation trend of available drilling cutting quantity per meter and drilling cutting quantity in the deep part of coal mass is used to predict rockburst.
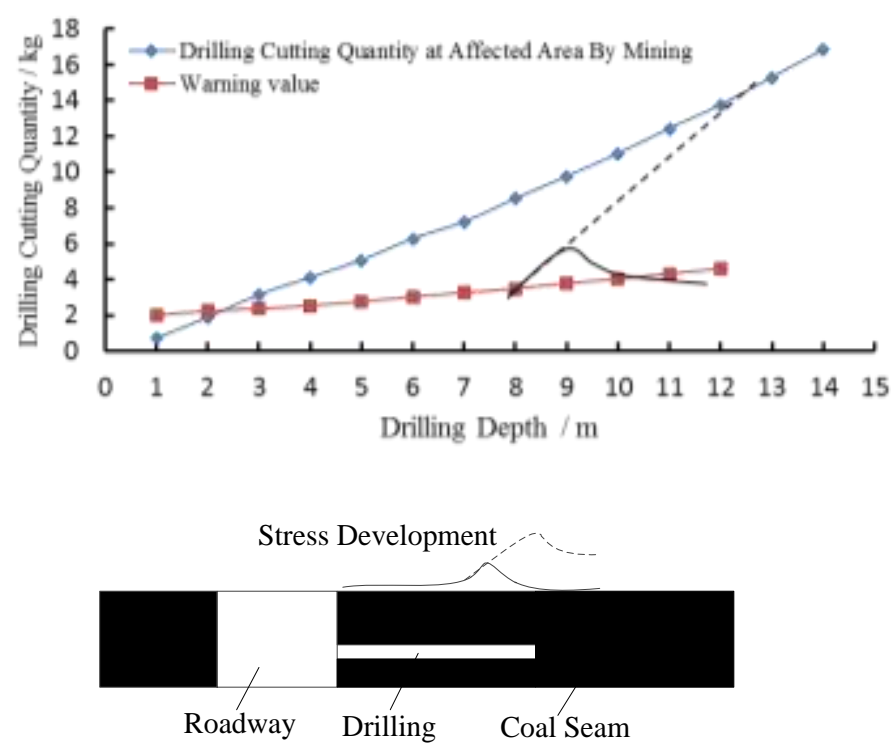

(a) Variation trend of drilling cutting quantity at unaffected area by mining
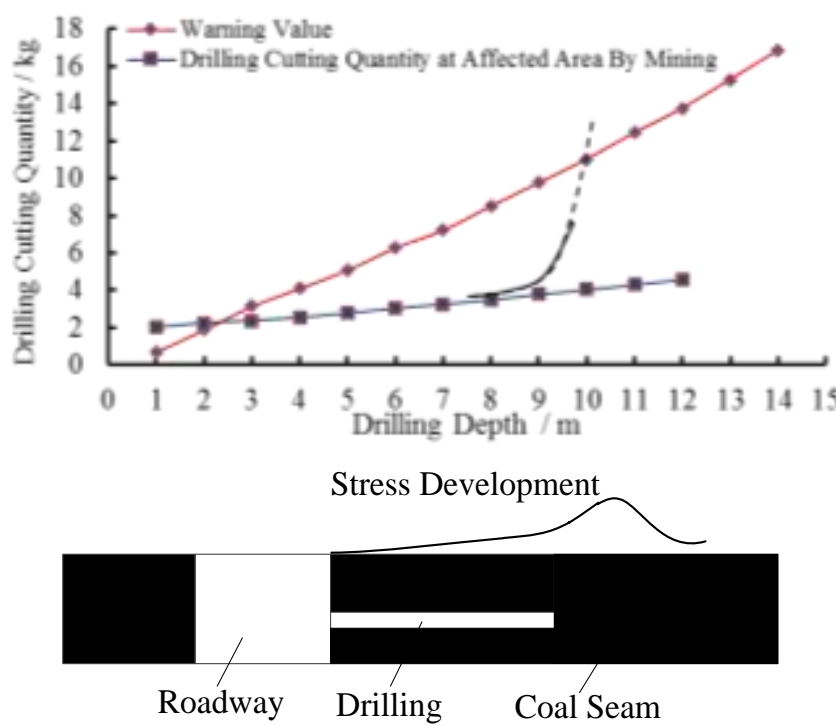

(b) Variation trend of drilling cutting quantity at affected area by mining

Fig. 6 Variation trend of drilling cutting quantity

When the drilling cutting quantity affected by mining reach the early warning indicator, the growth rate $\left(k_{1}\right)$ of the early warning indicator should be less than the growth rate $\left(k_{2}\right)$ of drilling cutting quantity within the certain range, it can be expressed as:

$$
k_{1}<k_{2}
$$

and: $k_{1}=y_{1}$ 


$$
k_{2}=\frac{y_{x_{1}}-y_{x_{2}}}{x_{1}-x_{2}}
$$

out if the drilling cutting quantity increment meets formula (7).

where $y_{x_{1}}$ is the actual drilling cutting quantity at $x_{1}$ position; $y_{x_{2}}$ is the actual drilling cutting quantity at $x_{2}$ position. When the depth difference between $x_{1}$ and $x_{2}$ is one meter, $k_{2}$ is the increment $\Delta$ of drill cuttings per meter.

It is worth noting that the energy required forming the rockburst and the drilling cutting quantity in the deep coal body are increased with increasing of the distance from the bottom of the borehole to the coal wall. Although the location of the rockburst is far away from the coal wall, the resistance is large and it is only a deep impact, its dynamic effect is the deep sound and vibration. The direct damage is limited. There is not necessarily the risk of a rockburst according to the growth trend of drilling cutting quantity in the coal body when the drilling cutting quantity reaches the early warning indicator. Only when the increasing trend of drilling cutting quantity reaches the increasing trend of warning indicator and the drilling cutting quantity meets the early warning indicator in the bumping danger zone, there is a risk of rockburst. Pressure relief measures must be carried out at this moment.

It is assumed that there is a rockburst hazard within the range of $x_{m}$ from the roadway coal wall, the increment of the drilling cutting quality should meet:

$$
\begin{array}{r}
\Delta_{1}>0.0416 x_{0}+0.61 \\
\Delta_{2}>\frac{y_{1\left(x_{m}\right)}-b}{x_{m}-x_{0}}
\end{array}
$$

where $b$ is the drilling cutting quantity at $x_{0}$ position; $\Delta_{1}$ is the increment of the drilling cutting quantity warning indicator at position $x_{0} ; \Delta_{2}$ is the increment of drilling cutting quantity compared with that of the previous meter at position $x_{0}$.

Therefore, only when the increment of drilling cutting quantity per meter meet the equation (1) and (2) at the same time, it is determined that there is a danger of rockburst at $x_{0}$ position. So the pressure relief measures will be required.

In the Xingcun coal mine, it is considered that the area with the range of $20 \mathrm{~m}$ away from the roadway has the dangerous of rockburst. So the increment of drilling cutting quantity should meet:

$$
\Delta_{1}>0.0416 x_{0}+0.61 \text { and } \Delta_{2}>\frac{20.52-b}{20-x_{0}}
$$

According to equation (4):

$$
\Delta>\frac{20.52-b}{20-x_{0}}
$$

where $\Delta$ is the increment of drilling cutting quantity at the range of $20 \mathrm{~m}$ away from the roadway.

When the abnormal increment of drilling cutting quantity appears during the mining process in Xingcun coal mine, the formula (7) is used to judge whether the growth trend of drilling cutting quantity can reflect the risk of rockburst. And the pressure relief measures will be carried

\section{CONCLUSION}

(1) Because the drilling depth is failure to reach the ideal depth and the drilling cutting quantity cannot completely reflect the stress distribution status in the coal body, there is a certain deviation in predicting the occurrence of rockburst by using common method of drilling bits. In addition, the common method of drilling bits has the characteristics of timeliness. Although the drilling cutting quantity can reflect the stress of the coal body at a certain extent, there is still the possibility of reaching the early warning indicator when the drilling monitoring area is still affected by mining.

(2) With the Xingcun coal mine as the study background, according to the growth trend of drilling cutting quantity and the drilling cutting quantity early warning indicator in the rockburst hazard zone, this paper proposes to utilize the increment of drilling cutting quantity per meter as the early warning indicator, and provides a real-time warning method. The growth rate of drilling cutting quantity is $k_{2}$ at position $x_{0}$, the increment $\Delta$ of the drilling cutting quantity relative to the previous one meter, should meet:

$$
\Delta_{1}>0.0416 x_{0}+0.61 \text { and } \Delta_{2}>\frac{y_{1\left(x_{m}\right)}-b}{x_{m}-x_{0}}
$$

(3) When the abnormal increment of drilling cutting quantity appears during the mining process in Xingcun coal mine, the formula (6) can be used to judge whether this range has a risk of rockburst based on the growth trend of drilling cutting quantity and drilling ratio.

\section{REFERENCES}

[1] Liu Yongxi, "Analysis on Problems Existed in Gas Content Measurement with Drilling Cuttings Method and Improvement," Coal science and Technology, vol. 42, no. 06, pp. 136-139, 2014.

[2] Lv Jinguo, Jiang Raodong and Zhao Yixin, "Hierarchical monitoring for coal bumps and its study and application of early warning methods," Journal of China coal society, vol. 38, no. 07, pp. 1161-1167, 2013.

[3] Su Shijie, "Optimization of Using Drilling Bits Method to Monitor Rockburst Hazard Indicators at Water Pre-injection Working Face," Safety in Coal Mines, vol. 44, no. 05, pp. 174-176, 2013.

[4] He Ye, Cai Qingxiang and Dou Linming, "Hazards of rockburst in island coal face and its control in coal mine jining No.2," Rock and Soil Mechanics, vol. S2, pp. 593-5962003.

[5] Li Jingda, Wei Quande and Jia Mingkui, "Method of Large Diameter no.01, pp. 126-129, 2016.

[6] Cui Naixin, Li Zhonghua and Pan Yishan, "Study on index of drilling bits for coalbed rockburst influenced by gas," Journal of Liaoning Technical University, vol. 02, pp. 192-193, 2006.

[7] Pan Yishan, Ling Zhonghua and Zhang Mengtao, "Distribution type mechanism and prevention of rockburst in China," Chinese Journal of Rock Mechanics and Engineering, ,vol. 22, no. 11, pp. 1844-1851, 2003.

[8] Qu Xiaocheng, Jiang Fuxing and Yu Zhengxing, "Rockburst monitoring and precaution based on equivalent drilling research and its applications," Chinese Journal of Rock Mechanics and Engineering, vol. 30, no. 11, pp. 2346-2351, 2011.

[9] Lu Zhen-yu, Dou Linming and Xu Xuefeng, "New discovery on drilling cuttings method to detect surrounding rock stress of mine roadway and predict mine pressure bumping dangers," Coal Engineering, vol. 1, pp. 72-74, 2011 Cutting Inspection and Its Application," Safety in Coal Mine, vol. 47, 
[10]Feng Enjie, LI Weiqing, "Practice and understanding of the prevention from rockburst in abutment area," Coal Mining Technology, vol.8, no.2, pp. 64-66, 2003.

[11] Yin Guangzhi, Li xiaoquan and Zhao Hongbao, "In-situ experimental study on the relation of drilling cuttingsweight to ground pressure and gas pressure," Journal of University of Science and Technology Beijing, vol. 32, no.1, pp. 1-7, 2010.

[12]Zhang Mengtao, Xu Zenghe and Pan Yishan, "A united instability theory on coal( rock) burst and outburst," Journal of China coal society, vol. 16, no.4, pp. 48-53, 1991.

[13]Zhao Benjun, Zhang Mengtao, "The study and application of the drilling method," Journal of Fuxin Mining Institute, pp.13-28, 1985. 